\title{
Supply Chain Decarbonisation in Shipping and Logistics Transportation
}

\author{
Eugene Y. C. Wong \\ Hang Seng Management College \\ Email: eugene.wong@oocl.com \\ Henry Y. K. Lau \\ Department of Industrial and Manufacturing Systems Engineering, The University of Hong Kong \\ Email: hyklau@hku.hk \\ Josephine S. C. Chong \\ The Chinese University of Hong Kong \\ Email: chongsc@cuhk.edu.hk
}

\begin{abstract}
The development and implementation of decarbonisation in shipping and logistics transportation is crucial to reduce greenhouse gas emissions from the perspective of products, supply chain, and organizations. There are increasing research interests on supply chain decarbonisation initiated by severe climate change, environmental awareness, government policy pressure, and corporate sustainability responsibility. A decarbonisation framework is developed as backbone for the implementation of greenhouse gas emission reduction in freight transport. The framework includes the introduction and review of the life cycle assessment, performance measurement metric, model emission targets, implementation, and monitoring tools. Carbon dioxide life cycle assessment is discussed with a recent example of a global fortune 500 corporations. Latest development and examples of carbon auditing and carbon calculator are presented. A review on the recent decarbonisation technology development and industrial practice is conducted with examples from companies from global 500. The analysis in the paper provides useful means for the future direction needed towards reducing the greenhouse gas emission in supply chain and logistics, with consideration on technology, education, corporation social responsibility, public environmental awareness, and government measures.
\end{abstract}

Index Terms-Decarbonisation, supply chain, greenhouse gas, carbon auditing, carbon calculator.

\section{INTRODUCTION}

Doherty (2009) estimated the amount of greenhouse gas (GHG) emission created by logistics and transportation activities [1]. Of the 50,000 mega-tonnes of annual carbon dioxide $\left(\mathrm{CO}_{2}\right) \mathrm{GHG}$ emissions created by human activities, about 2,800 mega-tonnes are due to logistics and transportation activities. Among the total emission volume from various modes of transportation, road freight accounts for the largest percentage with 57\%

Manuscript received November 19, 2012; revised January 1, 2013; accepted January 30, 2013. of the total volume. Ocean freight is accountable for $17 \%$, next, air and rail freight. Besides transportation logistics, retail and manufacturing logistics are also accountable for about $17 \%$ of the total volume, in which mineral and food products are major sources of transport emission. There are also assessments using emissions intensity per tonne$\mathrm{km}$, showing that air freight is considerably more carbon intensive than road. Rail and ocean freight are comparatively better carbon efficient modes. Governments and international organizations are setting GHG emission reduction targets, introducing measures, and implementing programmes (WBCSD/WRI, 2004) to improve the situation [2] [3] [4].

This paper describes the methodology and examples of $\mathrm{CO}_{2}$ emission life cycle assessment, proposes a decarbonisation framework, and provides an update on latest supply chain decarbonisation technologies, government policies, and industrial practices. It also recommends the future direction needed towards reducing greenhouse gas emission.

\section{II. $\mathrm{CO}_{2}$ EMISSION LIFE CYCLE ASSESSMENT (LCA)}

The Energy Independence and Security Act (EISA) (2009) defines life cycle GHG emission as the aggregate quantity of GHG emissions, included direct emissions and significant indirect emissions such as significant emissions from land use changes [5]. The aggregate quantity covers the full fuel lifecycle, including all stages of fuel and feedstock production and distribution, from feedstock generation or extraction through the distribution, delivery and use of the finished fuel to the ultimate consumer. The mass values for all GHGs are adjusted to account for their relative global warming potential [6] [7] [8].

NEC Corporation, a leading Japanese multinational company in the IT integration and network technologies, shows active initiatives in ascertaining and measuring $\mathrm{CO}_{2}$ emissions over the life cycle of its business operations. The cycle is assessed from materials 
procurement to production, warehousing, transportation, distribution, and customer use. This measurement covers its various plants and buildings, including its 6 plants, 3 laboratories, 23 manufacturing subsidiaries, 41 service and software subsidiaries, and 15 independent affiliates, as well as its suppliers during the raw materials extractions. The data collection and measurement on $\mathrm{CO}_{2}$ emission in NEC is mature and well developed, assisting the company to start various initiatives and solutions to reduce $\mathrm{CO}_{2}$ emission. By 2011, NEC was able to reduce its $\mathrm{CO}_{2}$ emissions by 2.12 mission tons. NEC continues to achieve its objective by undertaking energy-saving activities on all of its products. It aims to achieve topclass energy-saving products so that it can accomplish the milestone of "Improving the energy efficiency of products by $80 \%$ on a weighted average of all products in FY 2018", declared in the "NEC Group Environmental Management Action Plan 2017/2030" (NEC Corporation, 2010) [9]. Wal-Mart Stores is also one of the pioneers of life cycle analysis by developing a global database on product life cycles from raw materials to disposal.

\section{DECARBONISATION FRAMEWORK FOR FREIGHT TRANSPORT}

Logistics companies, especially logistics providers, truckers, feeder companies, and carriers, should set up measurement performance indicators and data centres to integrate and analyze the data collected for setting up various environment initiatives. This facilitates the life cycle assessments, target setting, decarbonisation program implementation, carbon auditing, sustainability index review, and international guidelines setting, forming the core elements of decarbonisation framework for freight transport.

\section{A. Measurement Metric}

The measurement of $\mathrm{CO}_{2}$ emissions could be carried out in two ways. It could be done mainly by estimating the quantity of fuel consumed times efficiency ratio, i.e. emissions per gallon, or by estimating the kilometres travelled multiplied by estimates of average emission. The two measurements serve as basis for carbon foot printing on a supply chain process or product. Care should be taken when referring to the standards. Clean Cargo Working Group (CCWG) uses aggregated data as a base. The emission factors are calculated based on actual fuel consumption, actual distance sailed, and nominal vessel cargo capacity. Energy Operator Indicator (EEOI) is calculated on the basis of fuel consumed, cargo transported, distanced sailed, and carbon emission factors [10] [11].

\section{B. Carbon Auditing}

The term carbon auditing starts to be used commonly in the recent years. A systematic measurement and audit on the GHG emission from a supply chain, product, or organization is bringing into shape by various organizations, including World Business Council for Sustainable Development (WBCSD), CCWG, British Standards Institution (BSI), and International
Organization for Standardization (ISO). Companies refer to the methodology and measurement to carry out audit. Orient Overseas Container Line (OOCL) engaged the American Bureau of Shipping (ABS) in March 2012 to complete an independent audit of the OOCL Carbon Calculator using the CCWG verification standard. A total of eleven vessels were selected for sampling and verification. The aim of the audit was to help to ensure quality and promote transparency and credibility of the disclosure of vessel emissions.

\section{Carbon Calculator}

Logistics and transportation firms are launching carbon calculators to increase visibility and allow instant measurement on the carbon emission of each shipment from its origin to destination. The carbon calculator provided is a tool to measure carbon emissions from all the modes of transportation, including truck, rail, barge, and vessel, on each shipment from its origin to destination. It is usually in terms of kilograms along the distance and TEU/weight involved. Vickie and Thomsen (2012) [12] indicates in SeaIntel Maritime Analysis that nine carriers have launched online $\mathrm{CO}_{2}$ calculators, they are Hanjin, COSCO, Hyundai, OOCL, Hapaq Llyod, Hamburg Sud, NYK, STX Pan Ocean, and Unifeeder. The analysis concludes that there is a methodical issue on carriers with different methodologies on the calculation. Some of them are using methodology provided by the CCWG while a few of them refers to the EEOI. The analysis compares five carriers, namely OOCL, Hapaq Lloyd, NYK, Hanjin, and HMM, using common methodologies and shows shipper could reduce his $\mathrm{CO}_{2}$ footprint by up to $45 \%$ in Trans-pacific Trade by changing his carrier portfolio. Besides carriers, other logistics providers, including Damco and DB Schenker have also provided online $\mathrm{CO}_{2}$ calculators for their customers.

Using OOCL as an example, the company announced the launch of the OOCL Carbon Calculator on April 2010. The calculator is designed to assist OOCL customers in measuring the carbon dioxide $\left(\mathrm{CO}_{2}\right)$ emissions in their supply chain. OOCL $\mathrm{CO}_{2}$ Index indicates the average carbon dioxide $\left(\mathrm{CO}_{2}\right)$ emitted per operating unit measured in $\mathrm{kg} \mathrm{CO}_{2} / \mathrm{TEU}-\mathrm{km}$ or $\mathrm{kg} \mathrm{CO}_{2} / \mathrm{TON}-\mathrm{km}$. For vessels, indices are calculated using actual fuel consumption, actual distance sailed and nominal vessel cargo capacity. Cargo capacity is represented by two different unit systems, TEU (Twenty-foot Equivalent Unit) and TON (cargo weight), thus translating to two options for users to calculate emissions. Hanjin Shipping offers similar carbon calculator that can be calculated by route, B/L number, or customer's specific data. Damco, the combined logistics brand of A.P. Moller-Maersk, also launched an online carbon calculator in September 2011 to enable shipper to measure the carbon dioxide emissions for products shipped by ocean and air.

\section{Environmental Sustainability Index}

Environmental Sustainability Index (ESI) is a composite index tracking various performances on the financial, environmental, corporate governance, or 
leadership perspective of the leading sustainability-driven companies. There are measurements with reference to financial performance in the stock exchange market, including Dow Jones Sustainability Index (DJSI) in U.S., Hang Seng Corporate Sustainability Index (HSCSI) in Hong Kong, Istanbul Stock Exchange and NASDAQ OMX CRD Global Sustainability Index in US. There are also indicators focusing on the performance of a company on its action towards climate change mitigation, for example, Carbon Performance Leadership Index (CPLI), and Carbon Disclosure Leadership Index (CDLI) in Global 500.

\section{E. International Standards and Guidelines}

ISO14064-1:2006 is an international standard addressing the quantification, reporting, and auditing of greenhouse gas emissions. It provides an overview of the structure of the standard and presents the key aspects of the design and application of the developed standard [13]. It aims to provide a guideline for private and public sector in developing GHG inventories for their organization as well as a foundation for policy makers for initiatives to address the global environmental challenge of climate change [14]. ISO14065 lists the requirements for greenhouse gas validation and verification bodies for use in accreditation or other forms of recognition in 2007 [15].

BSI (2008) published PAS 2050: Specification for the Assessment of the Lift Cycle Greenhouse Gas Emissions of Goods and Services [16]. WBCSD and World Resources Institute (WRI) also issued GHG protocol, the Greenhouse Gas Protocol: A corporate accounting and reporting standard (WBCSD/WRI, 2004) [17]. Carbon Trust (2006) provided a guideline on carbon auditing considered the carbon footprints in the supply chain [18].

During the carbon emission reduction programs, carbon auditing, or development of the carbon calculator, company vessel or vehicle emission factors are calculated with reference to these guidelines, including the $\mathrm{CO}_{2}$ calculation methodology developed by the International Maritime Organization (IMO) and CCWG.

\section{DeCARbonisation TEChNOLOGY}

Development of decarbonisation technology increases the pace of minimizing greenhouse gas emission. The fuel-cell technology and shoreside electric power units from Nippon Yusen Kabushiki Kaisha (NYK Line) and idle-control technology from BNSF Railway shows potential solutions on greenhouse gas emissions.

Nippon Yusen Kabushiki Kaisha (NYK Line), a Japanese shipping line, aims to achieve zero emission by 2050 through the implementation of the concept ship NYK Super Eco Ship 2030. With the volume of goods transported by sea being increased $3 \%$ each year, NYK Line has started to develop its program, using Fuel Cell Technology as an alternative cleaner energy in order to reduce $\mathrm{CO}_{2}$ emission.

The greenhouse gas emission during the onboard generator operations of vessels in port affects the environment. The supply of electric power from the shore to an electric power unit onboard reduces the emission of $\mathrm{CO}_{2}$. NYK Line has started to use its vessel NYK Atlas to receive full shoreside power in 2007 at Yusen Terminals in the port of Los Angeles. NYK Line has also installed container-shipped shoreside electric power units to enable its fleet of large containerships to receive shoreside electric power.

BNSF Railway developed an idle-control mechanism on locomotives to reduce air emissions and fuel consumption by automatically shutting down locomotives that are not being used. There are over 6,600 locomotives which will be further installed with the idle-control technology.

\section{CORPORATE SOCIAL RESPONSIBILITY ON DECARBONISATION IN LOGISTICS}

Current corporate social responsibility on supply chain decarbonisation is initiated by large corporations with adequate resources to carry out various means of reducing greenhouse gas. The initiation on green logistics from companies is often due to severe climate change, environmental awareness, and government policy pressure. Companies with inadequate resources or lack of environmental awareness might find difficult to implement decarbonisation programs. Corporate under severe economic market changes will also put priority on costs than environmental measures. Good industrial practices on supply chain decarbonisation are important to influence neighbours to start concerning their carbon emission level and carrying out necessary measures [19]. Some of the practices from global fortune 500 corporations are described below.

Maritime, transportation, and logistics corporations in global 500 involve various mode of business, including freight, marine, truck, rail, air, and Third-Party Logistics (3PL). Most of them show environmental protection initiatives and concerns on $\mathrm{CO}_{2}$ emissions. They are BNSF, Deutsche Post, U.S. Postal Service, United Parcel Service (UPS), A. P. Moller-Maersk Group, Fedex, SCNF, and China Ocean Shipping. There are also other global corporations, like BNSF, OOCL, NYK, Hanjin, DHL, and DB Schenker, carrying out various programs to reduce $\mathrm{CO}_{2}$ emissions. Maersk supports and applies the theory of Pamlin (2009) [20] on switching from air freight to sea freight to reduce $\mathrm{CO}_{2}$ emissions for transporting goods across long distance. Maersk proposes using carbon distance as measurement and guideline for future global transport systems to meet a limited carbon budget. The company carries about various carbon reduction initiatives, include StarCare and Gas Flare Reduction. Green initiatives from other companies include GoGreen program and carbon accounting and controlling system in DHL, carbon calculator, Winds Charter Intiative, Clean Truck Programs, and Port of Long Beach's Green Flag in OOCL, and Supply Chain Carbon Calculator System in Hanjin Shipping.

Retail logistics is one of the major elements in the supply chain. There are at least eight retails fall into top 200 of the global fortune 500 in 2011, including WalMart Stores, Carrefour, Costco Whilesale Corporation 
(Costco), Home Depot, Target, Best Buy, Woolworths, and Sears Holdings. Wal-Mart, being the top spot in the global 500 list, is the pioneer company that leads the role of corporate sustainability. Wal-Mart announced in 2005 its global environmental measures to increase energy efficiency, included the reduction of greenhouse gas emissions by $20 \%$ in seven years. It also launched its Sustainability Index in 2009 in an effort to assume accountability for its products' origins and increase the visibility and transparency of the product to its customers. Carrefour, an international hypermarket chain headquartered in France, reduces its logistics environmental impact as one of its commitments to the environment. It is carried out by optimizing its transport and logistics activities with 43,800 fewer trucks on the road, resulting 14,300 tonnes of $\mathrm{CO}_{2}$ saved in France in 2009. Carrefour looks for alternative means of transport for deliveries to group warehouse, e.g. river and rail transport. The group also set up consolidation platform in 2008 to reduce its suppliers mileage travelled in the road, saving the percentage in $\mathrm{CO} 2$ emissions per pallet transported. Costco has developed and implemented a corporate energy policy by implementing a program for GHG emission reduction in 2009. A number of giant retailers start to audit and report their carbon footprint with the use of GHG Protocol's Corporate Accounting and Reporting Standard discussed in Section IIIB, including Costco and Home Depot [21].

\section{EDUCATION AND PARTNERSHIP ON DECARBONISATION}

Supply chain decarbonisation covers technology, environment, and logistics aspects. The development needs joint effort from various parties in order to put ideas into real implementation. Collaboration among nonprofit organization, industrial corporations, and universities becomes the latest trend. DHL and National University of Singapore (NUS) jointly established Sustainable Supply Chain Centre Asia Pacific (SSCCAP) in 2010 [22]. The development of NYK Super Eco Ship 2030 is jointly investigated by Monohakobi Technology Institute (MTI), Elomatic, a marine consulting company in Finland, and Garroni Progetti S.r.l., a ship designer in Italy. The OOCL Carbon Calculator is developed in OOCL with The Hong Kong Polytechnic University.

The increase in awareness in the industry triggers the need of educational bodies starting courses about green logistics, including modules on greenhouse gas emissions and supply chain decarbonisation. Universities from U.K. and U.S. have started similar lectures on this subject in the recent years. Academic advisors and researches have been invited to Asia for seminars to share their experiences.

\section{CONCLUSION}

A supply chain decarbonisation framework, from measurement metric to monitoring tools, is developed to provide a foundation of implementing greenhouse gas emission reduction programs. The carbon dioxide emission life cycle assessment is discussed with an example from NEC Corporation. Principles and examples of carbon auditing and carbon calculator are presented. Current technology development and industrial practices are reviewed with examples from various global 500 corporations. The analysis in the paper shows a milestone of the current supply chain decarbonisation progress in the industry and provides an indication on future direction towards greenhouse gas emission reduction in supply chain and logistics, considered the corporate sustainability, climate change, government measures, technology development, and educational need.

\section{REFERENCES}

[1] S. Doherty, "Supply chain decarbonization, the role of logistics and transport in reducing supply chain carbon emissions," World Economic Forum, January 2009.

[2] World Business Council for Sustainable Development and World Resources Institute (WBCSD/WRI), "The greenhouse gas protocol: A corporate accounting and reporting standard," revised edition, World Business Council for Sustainable Development, Geneva and World Resources Institute, Washington, DC, 2004.

[3] J. Sarkis, Greening the Supply Chain, London, Springer, 2006.

[4] A. C. McKinnon, S. Cullinane, M. Browne, and A. Whiteing, 2010, Green Logistics: Improving the Environmental Sustainability of Logistics, Kogan Page Publishers.

[5] Energy Independence and Security Act (EISA), "Renewable Fuel Standard for 2009," Issued Pursuant to Section 211(o) of the Clean Air Act (CAA or the Act), 2009.

[6] R. J. Cole, G. Lindsey, and J. A. Todd, "Assessing life cycles: Shifting from green to sustainable design," in Proc. International Conference Sustainable Building 2000, Maastricht, The Netherlands, 22-25th October 2000. Proc, Sustainable Buildings, 2000.

[7] A. C. Aycaguer, M. L. On, and A. M. Winer, "Reducing carbon dioxide emissions with enhanced oil recovery projects: A life cycle assessment approach," Energy Fuels, ACS Publications, 15 (2), pp 303-308, 2001.

[8] D. Weisser, "A guide to life-cycle greenhouse gas (GHG) emissions from electric supply technologies," Energy, vol.32, Issue 9, Pages 1543-1559, September 2007.

[9] NEC Corporation, NEC Group Environmental Management Action Plan 2017/2030, 2010.

[10] T. Wiedmann and J. Minx, "A definition of 'carbon footprint,," ISA UK Research Report, 2007.

[11] N. Andrieu and L. Weiss, Transport Mode and Network Architecture: Carbon Footprint as a New Decision Metric, 2008.

[12] V. Perez and M. B. Thomsen, SeaIntel Maritime Analysis, 4 March 2012, Issue 50, 2012.

[13] ISO14064-1:2006, Greenhouse gases -- Part 1: Specification with guidance at the organization level for quantification and reporting of greenhouse gas emissions and removals, ISO 14000, Environmental management, 2006.

[14] J. Wintergreen and T. Delaney, ISO14064, International Standard for GHG Emissions Inventories and Verification, 2007. Available: http://www.epa.gov/ttn/chief/conference/ei16/session13/wintergre en.pdf

[15] ISO 14065, Greenhouse gases -- Requirements for greenhouse gas validation and verification bodies for use in accreditation or other forms of recognition, ISO 14000, Environmental Management, 2007.

[16] British Standards Institution, PAS 2050: Specification for the Assessment of the Lift Cycle Greenhouse Gas Emissions of Goods and Services, BSI British Standards, London, 2008,

[17] World Business Council for Sustainable Development and World Resources Institute (WBCSD/WRI), The Greenhouse Gas Protocol: A corporate accounting and reporting standard, revised edition, World Business Council for Sustainable Development, Geneva and World Resources Institute, Washington, DC., 2004.

[18] Carbon Trust, Carbon footprints in the supply chain: The next steps for business, November 2006. 
[19] S. Emmett and V. Sood, Green Supply Chains: An Action Manifesto, John Wiley and Sons, 2010.

[20] Pamlin and Dennis, 12 illustrative transformative low-carbon solutions, Transformative Solution Leadership, 2009.

[21] J. Sinegal, Corporate Sustainability Report 2009, Corporate Sustainability and Energy Group, 2009.

[22] Deutsche Post DHL, "Delivering tomorrow: Towards sustainable logistics," October 2010.

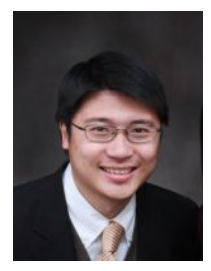

Eugene Y. C. Wong is a Manager with the Orient Overseas Container Line Ltd., focusing on traffic, network planning, and allocation optimization on Trans-Pacific Trade. Dr. Wong received his BEng and $\mathrm{PhD}$ from The University of Hong Kong and MSc from The University of London. Prior to joining the OOCL, he was an Engineer working in the Philips Semiconductor and Associate Consultant working in the Hong Kong Productivity Council. Dr. Wong's research interests lie in the areas of supply chain and maritime operations, operations research, artificial intelligence, and quality management systems.

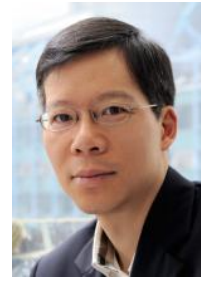

Henry Y. K. Lau is an Associate Professor with the Department of Industrial and Manufacturing Systems Engineering, The University of Hong Kong. Dr. Lau received his BA in Engineering Science and DPhil in Robotics from the University of Oxford, and prior to joining the University of Hong Kong, he was a Senior Systems Engineer working in the nuclear industry in England. Dr. Lau's research interests lie in the areas of artificial intelligence, industrial automation, process optimization, computer modeling and simulation.

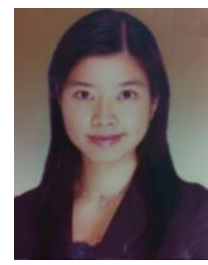

Josephine S. C. Chong is a medical specialist working in Department of Health of Hong Kong Special Administrative Region (HKSAR). Dr. Chong received her MBBS from the University of Hong Kong, and her fellowship from the Hong Kong Academy of Medicine. She also had worked in the metabolic unit of Royal Children Hospital in Melbourne, Australia. She is an honorary specialist of Prince of Wales Hospital and an honorary clinical tutor of the Chinese University of Hong Kong. One of Dr. Chong's research interests is the public health development. 